\title{
Research on evaluation model of the industry driven power of power enterprises based on the CGE module
}

\author{
Dai Hongcai ${ }^{1, a}$, Cai Tao ${ }^{1, b}$ and Song Haixu ${ }^{1, c}$ \\ ${ }^{1}$ SGCC Administrative Area, Future Science and Technology Park North Area, Beiqijia Town, \\ Changping, Beijing, China \\ adaihongcai@sgeri.sgcc.com.cn, ${ }^{b}$ caitao@sgeri.sgcc.com.cn, oonghaixu@sgeri.sgcc.com.cn
}

Keywords: CGE, Input-output Evaluation, Electric Grid

\begin{abstract}
With the development of economic, the association between different industries is becoming increasingly closer. Technical progress and technical alternative also become more and more frequently. At the same time, the impacts of environmental factors on the economic resources have become increasingly prominent. The impact of the power grid construction investment to the whole economic society will be extensive, including not only economic growth of various industries stimulated by investment, but also the efficiency improvement, resource conservation and environmental improvement brought by it. To evaluate the impact of the power grid construction investment, based CGE model, this paper build a new evaluation measurement model to reflect driven value and environmental value of the power grid enterprises, which contains economic factor, technology factor, and environment factor as well as the relation of different factors. It proved to be effective for evaluating the input-output for important program.
\end{abstract}

\section{Introduction}

With the development of economic, the association between different industries is becoming increasingly closer. Technical progress and technical alternative also become more and more frequently. At the same time, the impacts of environmental factors on the economic resources have become increasingly prominent. In this context, the impact of the power grid construction investment to the whole economic society will be extensive, including not only economic growth of various industries stimulated by investment, but also the efficiency improvement, resource conservation and environmental improvement brought by it [1-5]. This paper mainly discussed the driven value and environment value produced by the whole economic industries invested by power grid enterprises, and built a quantitative analysis model. Since we need to build a model which covers economy, technology, environment and various departments of the economic system and has the ability to reflect the mutual relationship between these departments, this paper, based on the CGE model, builds a evaluation measurement model to reflect driven value and environmental value of the Power grid enterprise. The grid is closely related to the electric power industry, and power supply is closely related to power generation. Therefore, building a model on energy consumption, carbon emissions and other pollutants is useful to study the impact of power grid enterprises to invest in environment [6-10]. 
The driven value and environmental value evaluation of power grid enterprises which based on CGE model mainly includes the following basic module structures: production module, income and demand module, international trade module, environment module, balanced closed module, dynamic module. Base on a model composed of the above modules, this paper finally accomplished the calculation of driven value and environment value of power grid enterprises.

The production module The electric power department can be divided into the power generating part and the power supply part. The power supply part can be further classified by the types of enterprises. The outputs of different power supply technologies can be replaced mutually and unlimitedly. On the other hand, the power generating part can be also further divided into thermal power generation and clean power generation. At the same time, the outputs of different power generation technologies can be replaced mutually and unlimitedly. Obviously, the segmentation of power generation technologies is beneficial to analyzing the supporting role of electric grid investments for the power generation of renewable sources.

The income and demand module The home-made and imported commodities, after imperfect substitution, are ultimately used for different demand for commodities, namely residents' consumption, government consumption, intermediate use, investment demand and inventory change.

The international trade module A part of the commodities of domestic consumption are homemade, while the other part comes from import. The home-made and imported commodities are composited by CES functions. On the other hand, parts of the commodities of domestic production are used for domestic sale, and the others are used for export. These commodities are composited by CET functions.

The environment module The calculation modes of energy consumption and emission of carbon and other pollutants are different in this module. The carbon emission, which is produced by energy consumption and fossil fuel combustion, is related to the intermediate inputs of fossil fuel, and can be estimated through the calculation of the unit energy consumption of intermediate input or the emission factor. The emissions of carbon and other pollutions (e.g. SO2, COD, etc), which are caused in manufacturing techniques (e.g. cement industry), are related to manufacturing output, and can be estimated by the emission factor of unit output.

The equilibrium closed module. Equilibrium of product market: Product market clearing can be achieved by the change of product relative price. Equilibrium of factor market: Market clearing can be achieved by the relative variation of the rates of return on each factor. Equilibrium of government income and expenditure: The government tax is fixed, and the government spending is endogenous. Equilibrium of international income and expenditure: The exchange rate is exogenous, and the import and export trade and foreign savings are endogenous.Equilibrium of investing savings: The savings is determined by investment, and the model is driven by investment.

The dynamic module Adopted the dynamic recursive model, mobilism is achieved by the main capital accumulation, labor force growth and technical progress. The current capital amount is endogenous, and equal to the depreciation that the previous capital amount minuses the previous depreciation and then plus the previous investment. The supply of total labor and the increase of TFP are both exogenous. 


\section{Data Foundation of the Model}

SAM table This study adopts the data of 2007 to build the SAM table, with its macroeconomic SAM table designing in accordance with the model structure. This table mainly includes following items: activities, electricity factor (such as thermal power generation, clean power generation, power supply enterprises), other sectors, factors, residents, businesses, government , investing savings, total income and total expenditure.

IO TABLE and the Industry Division Considering the simulation need of smart grid investment, we should consolidate input-output tables of 2007 by department. (Refer to tables of Department 135 and 42 for further consideration.). Keep those industry sectors which are closely related to the electricity industry, and merge the other minor sectors. The main criteria for department-selection are based on the requirements as follows: assume that there is a department, if the Direct Consumption Coefficient is bigger than 0.01 and its Partition Coefficient is bigger than 0.04, then keep it. (Some industry also can be retained after the merging . For example cement, lime and gypsum can be merged into the cement industry). The final results for the departmentalization are shown in the following table.

Table 1 Departmentation

\begin{tabular}{|c|c|c|c|}
\hline $\begin{array}{l}\text { Ordin } \\
\text { al }\end{array}$ & Industry & Ordinal & Industry \\
\hline 1 & Coal Mining and Washing & 16 & $\begin{array}{l}\text { Wire, cable, fibre optic cables and } \\
\text { electrical equipment manufacturing } \\
\text { Industry }\end{array}$ \\
\hline 2 & Oil Drilling & 17 & $\begin{array}{l}\text { Other electric machinery and } \\
\text { equipment manufacturing Industry }\end{array}$ \\
\hline 3 & $\begin{array}{l}\text { Natural-gas-extracting } \\
\text { Industry }\end{array}$ & 18 & Instrument Industry \\
\hline 4 & Metals Mining and Dressing & 19 & Thermal Power Generation \\
\hline 5 & $\begin{array}{l}\text { Nonmetal Minerals Mining } \\
\text { and Dressing }\end{array}$ & 20 & Clean Power Generation \\
\hline 6 & $\begin{array}{l}\text { Petroleum and nuclear fuel } \\
\text { processing Industry }\end{array}$ & 21 & Power Supply Enterprises \\
\hline 7 & Coking Industry & 22 & Heat Production and Supply Industry \\
\hline 8 & Chemical Industry & 23 & Gas Production and Supply Industry \\
\hline 9 & Cement Industry & 24 & $\begin{array}{l}\text { Water Production and Supply } \\
\text { Industry }\end{array}$ \\
\hline 10 & $\begin{array}{l}\text { Other non-metallic mineral } \\
\text { Enterprises }\end{array}$ & 25 & $\begin{array}{l}\text { Transportation and Warehousing } \\
\text { Industry }\end{array}$ \\
\hline 11 & $\begin{array}{l}\text { Pressing of ferrous metals } \\
\text { smelting }\end{array}$ & 26 & Financial Industry \\
\hline 12 & $\begin{array}{l}\text { Pressing of nonferrous } \\
\text { metals smelting }\end{array}$ & 27 & Other Industry \\
\hline 13 & Metal Products & & \\
\hline 14 & Transport Equipment & & \\
\hline 15 & $\begin{array}{l}\text { Power transmission and } \\
\text { distribution and controlling } \\
\text { device fabrication }\end{array}$ & & \\
\hline
\end{tabular}

\section{Construction of Input-output Model}


Line-equilibrium Model Measurement units in the column of the hybrid energy-environment input-output tables are not uniform. We can not calculate the sum of elements in the column direction, and only the line-equilibrium model is viable. The production and usage of productions in each sector have a balanced equation which is as follows.

$$
\sum_{j=1}^{n} z_{i j}+f_{i}=x_{i} \quad i=1,2, \cdots, n
$$

Where, ${ }_{i j}$ represents for the consumption of the product of the i-th production sector, which occurs in the production process of the $\mathrm{j}$-th production sector; ${ }_{i}$ represents for the number of final demand of the i-th sector; and ${ }^{x_{i}}$ represents for the total expense of the $\mathrm{i}$-th sector.

The formed equation of various pollutants is as follows.

$$
\sum_{j=1}^{n} p_{i j}+r_{i}=q_{i} \quad i=1,2, \cdots, m_{1}
$$

Where, ${ }^{p_{i j}}$ represents for the amount of the $\mathrm{i}$-th kind of pollutants emitted from the $\mathrm{j}$-th production sector; ${ }^{r}$ represents for the amount of the i-th kind of pollutants producted from final demand sectors such as residents; ${ }^{q}$ represents for the total generated amount of the i-th kind of pollutants.

The formed equation of various energy consumption is as follows.

$$
\sum_{j=1}^{n} e_{i j}+e_{i F}=e_{i} \quad i=1,2, \cdots, m_{2}
$$

Where, ${ }^{e_{i j}}$ represents for the amount of the i-th kind of energy consumed in the $\mathrm{j}$-th production sector; ${ }_{i F}$ represents for the amount of the i-th kind of energy consumed from final demand sectors such as residents; ${ }^{e_{i}}$ represents for the total consumption amount of the i-th kind of energy.

\section{Direct energy consumption coefficient}

$$
a_{i j}^{E}=\frac{e_{i j}}{x_{j}} \quad\left(i=1,2, \cdots, m_{2} ; j=1,2, \cdots, n\right)
$$

It represents the direct energy consumption of the $\mathrm{i}$-th energy when the $\mathrm{j}$-th department products unit production. When introducing $a_{i j}^{E}$ into formula (3), what we can conclude is as follows.

$$
A^{E} X+E_{F}=E
$$


Where, $A^{E}$ represents for a direct consumption coefficient matrix, $X, E_{F}, E$ respectively represents for the column vector of the total output、 column vector of energy consumption in the field of final demand, column vector of total energy consumption.

Complete further energy consumption Complete energy consumption refers to the sum of the direct and indirect energy consumption in the production process.

$$
\begin{gathered}
l_{i j}^{E}=a_{i j}^{E}+\sum_{k=1}^{n} a_{i k}^{E} a_{k j}+\sum_{t=1}^{n} \sum_{k=1}^{n} a_{i t}^{E} a_{t k} a_{k j}+\cdots \\
\left(i=1,2, \cdots, m_{2} ; j=1,2, \cdots, n\right)
\end{gathered}
$$

Where, ${ }^{{ }^{E} i}$ represents for complete consumption coefficient of the i-th kind of energy when the $\mathrm{j}$-th department products unit production. Its matrix form is as follows.

$$
L^{E}=A^{E}+A^{E} A+A^{E} A^{2}+\cdots=A^{E}(I-A)^{-1}
$$

\section{Pollutants production coefficient}

$$
a_{i j}^{P}=\frac{p_{i j}}{x_{j}} \quad\left(i=1,2, \cdots, m_{1} ; j=1,2, \cdots, n\right)
$$

It represents for the amount of the $\mathrm{i}$-th kind of pollutants when the $\mathrm{j}$-th department products unit production. When introduces $a_{i j}^{P}$ into formula (3), what we can conclude is as follows.

$$
A^{P} X+R=Q
$$

Where, $A^{P}$ represents for the matrix of pollutants production coefficient, $R, Q$ respectively represents for column vector of the amount of pollutants emissions in the field of final demand and column vector of the amount of total pollutants emissions.

\section{Pollutants full generation coefficient}

$$
\begin{gathered}
l_{i j}^{P}=a_{i j}^{P}+\sum_{k=1}^{n} a_{i k}^{P} a_{k j}+\sum_{t=1}^{n} \sum_{k=1}^{n} a_{i t}^{P} a_{t k} a_{k j}+\cdots \\
\left(i=1,2, \cdots, m_{1} ; j=1,2, \cdots, n\right)
\end{gathered}
$$

Where, ${ }^{P}{ }_{i j}^{P}$ represents for full generation coefficient of the i-th kind of pollutants when the $\mathrm{j}$-th department products per unit of production. Its matrix form is as follows.

$$
L^{P}=A^{P}+A^{P} A+A^{P} A^{2}+\cdots=A^{P}(I-A)^{-1}
$$

\section{Simulation Analysis}


Ultra high voltage ( UHV ) refers to AC $1000 \mathrm{kV}$ and above, and the positive and negative DC $800 \mathrm{kV}$ and above grade. UHV power transmission project is an important indicator that the construction and the overall operation of Chinese Electric Grid is moving on. It is an environment-friendly technologies. However, UHV impaction on energy environment is not simple and direct, on which there is an indirect correlation problem which can not be ignored. Therefore, the result of direct measure will underestimate the actual situation.

Input-output table is in the form of the balance sheet of a checkerboard, in order to reflect the links between the various productive sectors. Input-output model, established on the basis of the complex relationship between the various departments, can measure the direct and indirect effects completely and accurately. Therefore, How much it will save energy, reduce the number of emissions through Construction of UHV by Electric Grid and Chinese economic growth? The following describes the application method of this model as an example.

Table 2 Scenario design of UHV

\begin{tabular}{|l|l|}
\hline \multicolumn{1}{|c|}{ Scenario } & \multicolumn{1}{c|}{ Description } \\
\hline Baseline scenario(A) & No UHV \\
\hline UHV Scenario(B) & $50 \%$ of the electricity demand using UHV \\
\hline UHV Scenario(C) & $100 \%$ of the electricity demand using UHV \\
\hline
\end{tabular}

The environmental costs analysis of the building of the UHV line Compared to the baseline scenario who has no UHV, the first path will produce pollution and energy consumption, and it will consume raw materials, produce indirect pollution and energy consumption, when building the UHV. Therefore, the direct consumption coefficient, pollution emission coefficient, energy consumption coefficient of machinery and equipment manufacturing in UHV construction will change. Then the coefficients of related departments (such as departments of raw materials) also will change. And it will bring structural changes to the direct consumption coefficient, pollution emission coefficient, energy consumption coefficient. The second path will reduce energy consumption and pollution from exhaust emissions which are brought with long-distance transport by rail and road of coal for power generation. So the indirect pollution and energy consumption from raw materials during transport will be reduced. Then, the direct effect to energy environment is the change of direct consumption coefficient, pollution emission coefficient and power coefficient of the transportation and warehousing. The coefficients of related departments (such as transportation equipment manufacturing industry) also will change. The change of each departments' energy consumption and pollution emissions during the UHV construction can be calculated by the formula 12, in order to measure the environmental costs.

The environmental benefits of UHV instead of the traditional method Compared to the baseline scenario who has no UHV, the third path can make a significant reduction in line losses by UHV. Therefore, with the same electricity demand, the final demand of generation sectors will reduce. The change of each departments' energy consumption and pollution emissions during the UHV construction can be calculated, in order to measure the environmental benefits of UHV.

\section{Conclusion}


The impact of the power grid construction investment to the whole economic society will be extensive, including not only economic growth of various industries stimulated by investment, but also the efficiency improvement, resource conservation and environmental improvement brought by it. Based on the analysis result, the construction of UHV by Electric Grid can make a significant reduction in line losses with the same electricity demand. On the whole, power projects, especially major projects UHV has a large industrial drive value and environmental value.

\section{References}

[1] DONG Cheng-zhang. Input-output analysis[M]. China Financial and Economic Publishing House, 2000.

[2] DUAN Zhi-gang, FENG Shan, YUE Chao-yuan. 2005. Analysis for impacts of income taxes reform based on CGE_-Illustrated by Guangdong . Journal of Systems Engineering, (4): 185-192.

[3] DUAN Zhi-gang, LI Shan-tong 2004. Computable general equilibrium model of structural change in Beijing. The Journal of Quantitative \& Technical Economics,(12): 86-94.

[4] Fan Ming-tai, Zheng Yu-xin, Ma Gang. 1998. Chinese CGE model: The basic structure and related issues (on). The Journal of Quantitative \& Technical Economics, (12): 39-47.

[5] Fan Ming-tai, Zheng Yu-xin, Ma Gang. 1999. Chinese CGE model: The basic structure and related issues (Part Two). The Journal of Quantitative \& Technical Economics, (4): 24-30.

[6] He Ju-huang, Shen Ke-ting, Xu Song-ling,2002, Carbon tax and carbon dioxide emissions of CGE model. The Journal of Quantitative \& Technical Economics, (10):39-47.

[7] He Ju-huang, Shen Ke-ting, Xu Song-ling,2002, Carbon tax and carbon dioxide emissions of CGE model. The Journal of Quantitative \& Technical Economics, (10): 39-47.

[8] HUANG Ying-na, GUO Zhen-ren, ZHANG Tian-zhu, WANG Xue-jun. 2005. Quantitative Analysis on the Feasibility of Energy - Environment Tax Implementation

in China with a CGE Model. URBAN ENVIRONMENT \&URBAN ECOLOGY, 18(2): 18-20.

[9] Huang Ying-na, 2003. Quantitative analysis of the effect of environmental policy implementation: CGE model in Chinese energy and environmental taxes and voluntary agreements Policy Analysis. Peking University: Physical Geography (PhD thesis).

[10] HUO Li-li, CONG Liang, ZHANG Zhe-ren, HE Jin. 2006. The Structure and Application of CDF_ CGE Model. The Journal of Quantitative \& Technical Economics , (1): 117-128. 